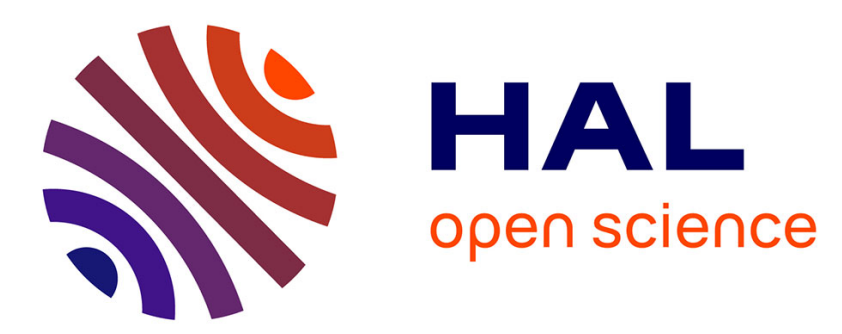

\title{
Development of a real-time hot-spot prevention using an emulator of partially shaded PV systems
}

\author{
M. Bressan, A. Gutierrez, L. Gutierrez, Corinne Alonso
}

\section{To cite this version:}

M. Bressan, A. Gutierrez, L. Gutierrez, Corinne Alonso. Development of a real-time hot-spot prevention using an emulator of partially shaded PV systems. Renewable Energy, 2018, Renewable Energy, 127, pp.334-343. 10.1016/j.renene.2018.04.045 . hal-01962921

\section{HAL Id: hal-01962921 \\ https://hal.laas.fr/hal-01962921}

Submitted on 9 Jan 2019

HAL is a multi-disciplinary open access archive for the deposit and dissemination of scientific research documents, whether they are published or not. The documents may come from teaching and research institutions in France or abroad, or from public or private research centers.
L'archive ouverte pluridisciplinaire HAL, est destinée au dépôt et à la diffusion de documents scientifiques de niveau recherche, publiés ou non, émanant des établissements d'enseignement et de recherche français ou étrangers, des laboratoires publics ou privés. 


\title{
Development of a real-time hot-spot prevention using an emulator of partially shaded PV systems
}

\author{
M. BRESSAN ${ }^{3}$, A. GUTIERREZ ${ }^{3}$, L. GARCIA GUTIERREZ ${ }^{3}$, C. ALONSO ${ }^{1,2}$ \\ ${ }_{1}$ CNRS ; LAAS ; 7 Avenue du Colonel Roche, F-31077, TOULOUSE, FRANCE. \\ 2 UNIVERSITE DE TOULOUSE ; UPS, INSA ; LAAS ; F-31400, TOULOUSE, FRANCE. \\ ${ }_{3}$ Department of Electrical and Electronic Engineering, Universidad of the Andes, Bogotá, Colombia \\ E-mail:m.bressan@uniandes.edu.co,corinne.alonso@laas.fr
}

\begin{abstract}
This work presents an emulation in real-time of the shaded PV systems with a hot-spot prevention. The PV model takes into account the photo-induced current contributions from unshaded and shaded sides thanks to parameters such as the shadow transmittance and the percentage area of the shadows. The use of shadow fault detection in real time is employed avoiding all form of hot-spot formation and PV cells power dissipation. The calculation uses a simple derivative equation able to give the area of detection in function of the PV module voltage. The implementation of the emulator in FPGA takes advantages as a result of their features of adaptability and parallel processing suitable for emulation of complex shading visible on PV systems. The emulation of the proposed PV model and the hot-spot prevention are validated through two experimental tests on PV modules.
\end{abstract}

Keywords: PV system, partial shading, bypass diode, shading factor, real-time emulation, hot-spot prevention

\begin{tabular}{|clcl|}
\hline Nomenclature & \multicolumn{1}{l|}{ Cell current } \\
$\delta$ & Shadow coefficient & $I_{0}$ & Dark saturation current \\
$\delta_{L}$ & Lowest shadow coefficient & $I_{d v}$ & Divergence current \\
$\delta_{n}$ & Calculated shadow coefficient & $I_{p h}$ & Photogenerated current \\
$\tau$ & Shadow transmittance & $I_{p h_{i}}$ & Illuminated $I_{p h}$ \\
$a$ & Constant & $I_{p h_{S}}$ & Shaded $I_{p h}$ \\
$a_{i}$ & Percentage of illuminated area & $I_{p h_{T}}$ & Total $I_{p h}$ \\
$a_{n}$ & Calculated area & $I_{p h_{T}}$ & Completely illuminated $I_{p h}$ \\
$a_{s}$ & Percentage of shaded area & $I_{s c}$ & Short circuit current for STC \\
$a_{s_{L}}$ & Lowest percentage of shaded area & $J$ & Density current \\
$k$ & Boltzmann constant & $J_{p h}$ & Photocurrent density \\
$m$ & Constant & $J_{p h_{i}}$ & Illuminated $J_{p h}$ \\
$n$ & Ideality factor of the diode & $M S E$ & Mean Square Error \\
$q$ & Magnitude of the electron charge & $R_{S}$ & Series resistance \\
$p_{b}$ & Black pixel & $R_{S h}$ & Shunt resistance \\
$p_{w}$ & White pixel & $S_{f}$ & Shading factor \\
$A_{c}$ & Cell area & $S T C$ & Standard Test Conditions \\
$A_{i}$ & Illuminated area & $T_{c}$ & Cell temperature \\
$A_{s}$ & Shaded area & $T_{S T C}$ & Temperature for STC \\
$C_{T_{i}}$ & Thermal current coefficient & & \\
\hline
\end{tabular}




\begin{tabular}{|clcl|}
\hline$G_{i}$ & Incident irradiance & $V$ & Cell voltage \\
$G_{s}$ & Irradiance for shaded area & $V_{b r}$ & Avalanche breakdown voltage \\
\hline
\end{tabular}

\section{Introduction}

The study of PV systems grew significantly in recent years more particularly in urban areas. PV systems can be affected by several external factors such as shadows. PV arrays in shading conditions not only decrease the produced energy [1-2] but also increase the risk of structural failures with the apparition of localized hot-spot [3]. A monitoring PV system gives accurate information about the behaviour of a PV plant more particurlarly in shading conditions. With the measure of the maximum DC power of a PV array, it is easier to perform some fault detection in real-time seeing the drop of the voltage and the current of the PV systems [4]. The development of practical fault detection approaches in photovoltaic (PV) systems, intended for online implementation permits to have a robust system and an important fault detection rate. In the study of Platon [5], the fault detection approach is based on the comparison between the measured and model prediction results of the ac power production. Chine [6] presents an automatic fault detection method for grid-connected photovoltaic (GCPV) analyzing the ratio between DC and AC power to identify some faults. Different types of faults are identified such as a fault in a photovoltaic module, a fault in a photovoltaic string, a fault in an inverter, and a general fault that may include partial shading, PV ageing, or MPPT error. The study of Serrano [7] shows a model using data mining techniques to assess the state of the PV (photovoltaic) generator classifying its state thanks to an algorithm without measuring ambient conditions. With the result of a $222 \mathrm{kWp} \mathrm{CdTe} \mathrm{PV} \mathrm{case,} \mathrm{it} \mathrm{is} \mathrm{shown} \mathrm{that} \mathrm{the} \mathrm{application} \mathrm{of} \mathrm{computing}$ learning algorithms can improved the management and performance of the photovoltaic generators finding faults during the PV performance. In the study of Silvestre [8], a procedure for automatic supervision, fault detection, and diagnosis of possible failure sources has been performed to minimize total or partial loss in the productivity of grid connected PV systems. Other study used a procedure for fault diagnosis in PV systems with distributed maximum power point tracking at module level—power optimizers (DC/DC) or micro-inverters (DC/AC) [9]. The work of Madeti [10] presents a new fault detection and diagnosis technique for solar photovoltaic (PV) systems operating under grid-tied and off-grid modes using local measurements and model predictive.

But it is important to minimize the use of DC or AC parameters such as predictive value of a PV systems for the fault detection in order to avoid the increase the cost and the complexity of the system. The fault detection in real time takes its advantage minimizing parameters.

The second aspect treats the presence of the partial shading which affects drastically the efficiency of the PV modules such as the presence of hot-spot.

A hot-spot refers to the portion of the cell with a higher temperature increase. In the study of Kim [11], it is shown that the hot-spot phenomena can lead to second breakdown or cell encapsulant damage although the activation of bypass diodes. An IR camera test proved a temperature increase of localized shaded PV cells in the study of Bressan [12]. Various simulation and experimental studies have shown the problem of modeling the thermal behavior of PV cells in hot-spot condition. In the study of Wang [13], five different connection configuration of PV cells have been studied to compare their performance under partial shading. In the same conditions of partial shading, a methodology of simulation is proposed optimizing the bypass diodes configuration to prevent hot-spot 
apparition in PV modules [14]. In the study of Daliento [15], an improved bypass approach based on a power mosfet and a diode has been proposed to reduce the hot-spot temperature in a presence of partial shading. To avoid the permanent damage of the shaded PV cells, the works of Rossi [16] proposed a hystérisis comparator to detect hot-spot apparation and validated in SPICE simulations. There exist other methods able to detect hot-spot, soiling and aging degradation [17-19]. A tool for the evaluation of I-V characteristics and energy yield of PV systems has been performed taking into account the sun position and the shading patterns [20]. This work can be solved through the optimized engines of commercial simulators (Matlab, PSPICE) with very low computation time in comparison to analogous numerical methods.

These studies show the importancy to develop real-time simulation methods for complex shaded PV systems and fault detection method to avoid all form of localized hot-spot.

PV emulators have been proposed in several studies to reproduce the shaded PV behavior using approaches from analog circuit [21]. The emulator approach is a real challenge to study the high non-linearity and the complexity of PV systems in partial shading. Moreover, the supervision and the real-time fault detection play an important part in this challenge.

In this paper, a methodology to emulate in real-time partially shaded PV systems is presented taking into account a shadow transmittance and the percentage of area of the shadow. This work validates the hot-spot detection method that consists to compare I-V curves in normal opeation with I-V curves in shaded operation [12]. The main objective of this detection is to accurately identify anomalies and hot-spot formation. The difference of the I-V curves shape permit to dissociate a homogenous shading of a non homogenous. The proposed methodology is implemented in a Field Programmable Gate Array (FPGA). The FPGA use is justified because of the apparition of DC-DC converter with the use of Gallium nitride power transistors which permit to get has greater -high efficiency, high power density and to achieve higher switching frequency [22]. The FPGA is selected as a computational device because of their adaptability and high speed processing features in order to provide a high speed fault detection. The advantage of FPGA implementation is the computation time of the shaded PV model and the hot-spot prevention.

The papers is organized as the following, section 2 presents the theoretical model for PV modules in normal and complex shading conditions. Section 3 presents the hot-spot prevention method allowing to separate the nonuniform shadow of a uniform. The simulation and experimentals results are discussed in the last section.

\section{PV system and hot-spot condition}

Partial shading generates severe mismatch leading to hot-spot apparition. These section introduces this phenomena and the appropriated theorotical model to characterize it accurately.

\subsection{Thermal cell dissipation due to shading: theory review}

Hot spots are a well-known problem in PV modules and strings that lead to individual cells or portions of a cell $\mathrm{t}$ o become reverse-biased and dissipate heat [23]. When a PV cell is covered in a string, the overall current becom es limited by the covered cell increasing its temperature. The affected cells are forced into reverse bias and starts to dissipate power and can lead to its destruction. In the study of Kim [24], most manufacturers do not take into a ccount the reverse breakdown characteristics. A phenomenon called second breakdown can occur that localizes $r$ 
everse current flow in a small portion of the cell and can lead to extreme cell temperatures and damage. An IR ca mera test has been performed to see the PV module behavior in short circuit and in open circuit equipped of bypa ss diodes in localized shading conditions [12]. A hot-spot area is shown at the level of the covered PV cell increa sing its temperature. The current in the PV module sub-string is limited by the shaded PV cell despite the activati on of the by-pass diode of the sub string. As a result, it operates under reverse-bias mode, dissipating power in th e form of heat. Where a cell dissipates power operating in the reverse bias with various kind of shading illuminati on, it is shown that the voltage breakdown of the shaded PV cell changes and tends toward 0. This implies the ap parition of hot-spot on the PV module.

To resume, non-uniform shading has an important impact on PV performances despite the activation of bypass diode. Hot spotting can lead to second breakdown or cell encapsulant damage and permanently degrade the PV panel or leads to safety concerns. Complex shading is difficult to characterize and to interact with power converters with high switching speed [25]. Knowing the shading area and the photoinduced transmittance will permit to understand the PV systems in partially shading conditions. A model is developed considering shadow patterns and it is validated firstly in Matlab. The final part consists to emulate the methodology in real-time to validate hot spot prevention method using FPGA.

\subsection{Classical solar cell model}

The photovoltaic effect is the conversion of light into electricity. The classic model of a PV cell is governed by E quation (1) [21]. Equation (1) can be used to acquire I-V curve, which shows the behavior of the current and the $\mathrm{V}$ oltage of a PV system.

$$
I=I_{p h}-I_{0}\left[\exp \left(\frac{\left(q\left(V+I \cdot R_{s}\right)\right)}{n k T}\right)-1\right]-\frac{V+I \cdot R_{s}}{R_{s h}}
$$

Where $I_{p h}$ is the photocurrent (A), $I_{0}$ is the dark saturation current (A), $n$ is the ideality factor of the diode (1 to 2) , $k$ is the Boltzmann constant $\left(1.3810^{-23} \mathrm{~J} /{ }^{\circ} \mathrm{K}\right), q$ is the magnitude of the electron charge $\left(1.60210^{-19} \mathrm{C}\right), T$ is the $\mathrm{t}$ emperature of the cell $\left({ }^{\circ} \mathrm{K}\right), R_{s}$ is the series resistance, $R_{s h}$ the shunt resistance.

However, most of the models in literature do not take into account the effect of the reverse bias. A more precise model is proposed by Bishop [26] which incorporates the avalanche effect as a non-linear multiplication factor that affects the shunt resistance current term, shown below:

$$
\begin{aligned}
& \left.I=I_{p h}-I_{0}\left[\exp \left(\frac{\left(q\left(V+I \cdot R_{s}\right)\right)}{n k T}\right)-1\right]-\frac{V+I \cdot R_{s}}{R_{s h}}-a \frac{V+I \cdot R_{s}}{R_{s h}}|1-| \frac{V+R_{s} \cdot I}{V_{b r}}\right)^{-m} \\
& \text { Multiplication factor on shunt } \\
& \text { resistance }
\end{aligned}
$$

Where $a$ and $m$ are constant, $V_{b r}$ is the avalanche breakdown voltage (V).

By studying different PV cells in reverse bias, Bishop has noted a different evolution of the current. The avalanche breakdown in reverse bias represented by a non-linear multiplication factor is shown in red in Equation (2). This factor affects the shunt resistance current term. Negative voltages for solar cells can occur at non-uniform 
illuminated PV generators, especially during partial shading of PV modules. The breakdown voltages for poly-Si cells are within the range $-12 \mathrm{~V}$ to $-20 \mathrm{~V}$, whereas for mono-Si cells the breakdown voltages can extend $-12 \mathrm{~V}$ to $30 \mathrm{~V}$ [27]. More precisely, when the PV module is partially shaded, the behavior of the I-V curve is different showing the reverse bias contrary to classic equation. In the study of Kim [24], experimental results have been performed using the open-circuit technique with a resistive load powered by two 20-cell PV strings with one cell partially shaded on a clear sunny day. An increase of the temperature of the shaded PV cell is shown thanks to an IR thermography. This experiment confirms that localized hot spotting is possible despite the activation of the bypass diode. The shadow properties are complex and difficult to treat. This next section presents the proposed model that considers shadow properties for describing the behavior of partially shaded PV systems.

\subsection{Proposed PV model for partially shaded conditions}

Partially shaded cells have two main shadow features as shown in Fig. 1. The first feature is the shadow geometry represented by $a_{s}+a_{i}=1$ with $a_{s}$, the percentage of shaded area and $a_{i}$, the percentage of shaded area. The second shadow feature is the optical properties represented by the shadow transmittance $\tau$ and shading factor $S_{f}$. The shadow transmittance is defined by the relation between the irradiance on the shaded area and the incident

irradiance $\tau=G_{s} / G_{i}$ [28]. The shading factor $S_{f}$ is defined by the shadow opacity where $0 \leq S_{f} \leq 1 . S_{f}=0$ means that the available irradiance shines on the PV cell; in contrast, $S_{f}=1$ means that all available irradiance is blocked by the shadow. Thus, $S_{f}+\tau=1$. The proposed model is explained more in details in the thesis works of Alonso Gutierrez between the LAAS-CNRS and the University of The Andes for designing multi-physics complex systems in embedded hardware [29].

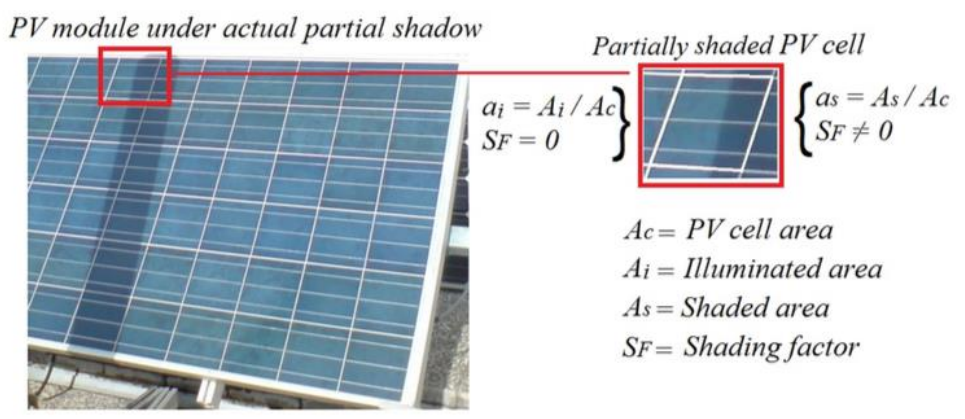

Fig. 2a shows a 3D

Fig. 1 : Partially shaded PV cell

schematic section of a partially shaded PV cell. Electron-hole pairs are generated when photons arrive at the $p-n$ junction in the illuminated area. As a result, a photogenerated current $I_{p h_{i}}$ is produced. In contrast, fewer photons can arrive at the $\mathrm{p}-\mathrm{n}$ junction in the shaded area; and thus, a lower photogenerated current $I_{p h_{S}}$ is produced. 


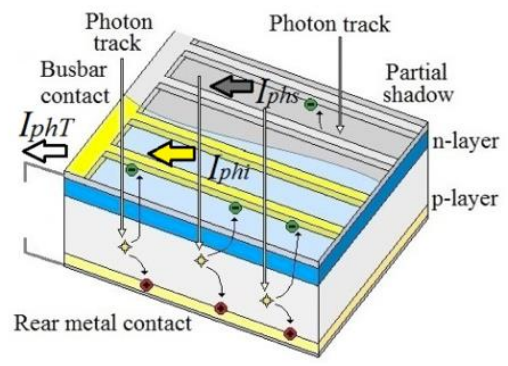

(a) Section of a partially shaded cell

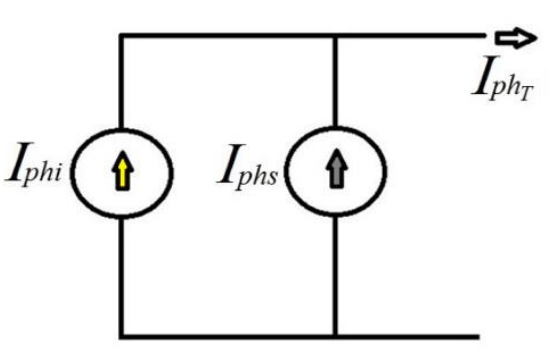

(b) Photogenerated currents

Fig. 2 : Photogenerated currents in partially shaded PV cell

$$
I_{p h_{T}}=I_{p h_{i}}+I_{p h_{s}}
$$

Given that $S_{f}+\tau=1$ and $a_{s}+a_{i}=1$,

$$
I_{p h_{T}}=I_{p h_{T i}}\left(1-a_{s} S_{f}\right)
$$

And on defining the shadow coefficient $\delta$ as :

$$
\delta=1-a_{s} S_{f}
$$

The obtained photogenerated current is

$$
I_{p h_{T}}=I_{p h_{T i}} \delta
$$

Where $I_{p h_{T i}}$ is the photogenerated current for completely illuminated conditions:

The Equation (2) becomes :

$$
I_{p h_{T i}}=\left[I_{s C_{S T C}}+\left(C_{T i}\left(T_{c}-T_{S T C}\right)\right)\right] \frac{G_{i}}{G_{S T C}}
$$

$$
I=I_{p h_{T i}} \delta-I_{0}\left[e^{\left(\frac{q\left(V+I R_{S}\right)}{n k T}\right)}-1\right]-\frac{V+I R_{s}}{R_{s h}}\left[1+a\left(1-\frac{V+I R_{s}}{V_{b r}}\right)^{-m}\right]
$$


The solution of the Equation (10) describes the influence of the shadow coefficient $\delta$ on the I-V curve and power production. The following section presents the simulation and the model validation for several experimental conditions.

\subsection{Validation of the proposed model with experimental tests}

The objective of this test is to validate the proposed model under actual shaded conditions. The model is implemented in Matlab/Simulink@ $\odot$. The experiment comprises two types of shadows projected on the PV modules shown in Fig. 4. This test uses polycrystalline PV modules TE2200 shown in Table 1.

Table 1: TE2200 PV module specifications

\begin{tabular}{cc}
\hline Variable & Value \\
\hline Cell type & Mono crystalline \\
Maximum power rating $\left(P_{\max }\right)$ & $250 \mathrm{Wp}$ \\
Open circuit voltage $\left(V_{o c}\right)$ & $37.5 \mathrm{~V}$ \\
Short-circuit current $\left(I_{s c}\right)$ & $8.8 \mathrm{~A}$ \\
Voltage at maximum power $\left(V_{m p}\right)$ & $30.05 \mathrm{~V}$ \\
Current at maximum power $\left(I_{m p}\right)$ & $8.4 \mathrm{~A}$ \\
By-pass diodes & 3
\end{tabular}

An I-V curve tracer (model MP-160, EKO Instruments, Japan) is used to measure the current-voltage signals. A digital camera simultaneously records the shadow pattern. In addition, a pyrometer (model SP-Lite, Kipp \& Zonen, Netherland) is used to detect the solar irradiance and a thermographic camera is used to monitor the PV module temperature. The different steps for the experimental validation of the proposed model consists in measuring and recording I-V curves, solar irradiance, PV module temperature, and shadow patterns [27]. The analysis of shaded cells is performed thanks to the image processing methods. The contour selection of the shaded PV cells uses the histogram distribution. The image conversion to binary image is performed through the Otsu's method. Finally, the shaded area is calculated in the following equation :

$$
a_{s}=\frac{\sum p_{b}}{\sum p_{b}+\sum p_{w}}
$$

where $p_{b}$, the black pixels and $p_{w}$, the white pixels of the cell area.

The next step is to calculate the lowest shadow coefficient $\delta_{L}$ (Equation (12) and the shading factor $S_{f}$ (Equation (13). $I_{p h_{T i}}$ is calculated using the Equation (9), and $I_{d v}$ is measured at the first divergence-current point in the I$\mathrm{V}$ curve representing the bypass activation shown in Fig. 3.

$$
\delta_{L}=\frac{I_{d v}}{I_{p h_{T i}}}
$$




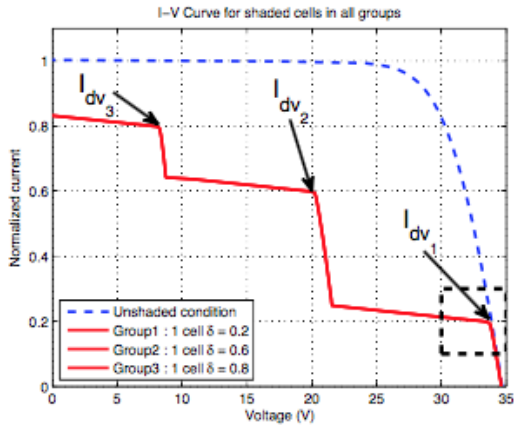

Fig. 3 : Shadow coefficient $\delta$ and contribution of partially shaded cells to I-V curve

191

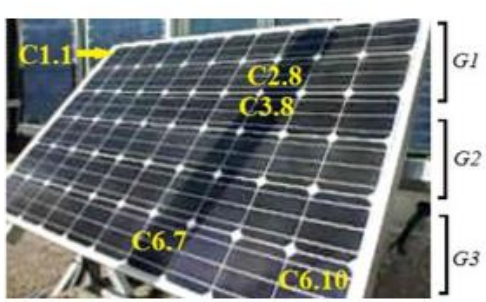

(a) Case 1, monocrystalline

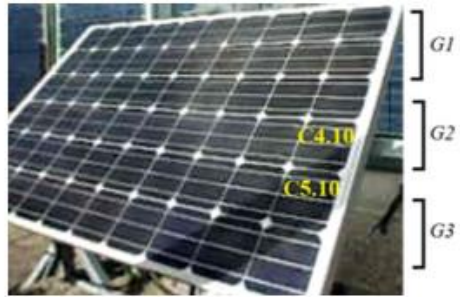

(b) Case 2, monocrystalline

Fig. 4 : Experimental tests for monocrystalline PV module

Table 2 : Shading factor results for PV module TE2200 under test

\begin{tabular}{ccc}
\hline Type & Monocrystalline \\
\hline & Case 1 & Case 2 \\
$G_{i}$ & $820 \mathrm{~W} / \mathrm{m}^{2}$ & $910 \mathrm{~W} / \mathrm{m}^{2}$ \\
$T_{c}$ & $31^{\circ} \mathrm{C}$ & $31^{\circ} \mathrm{C}$ \\
$I_{p h}$ & $7.07 \mathrm{~A}$ & $7.85 \mathrm{~A}$ \\
$I_{d v}$ & $2.16 \mathrm{~A}$ & $2.7 \mathrm{~A}$ \\
$\delta_{L}$ & 0.31 & 0.34 \\
$a_{s L}$ & 0.98 & 0.91 \\
\hline$S_{f}$ & $\mathbf{0 . 7 0}$ & $\mathbf{0 . 7 2}$
\end{tabular}




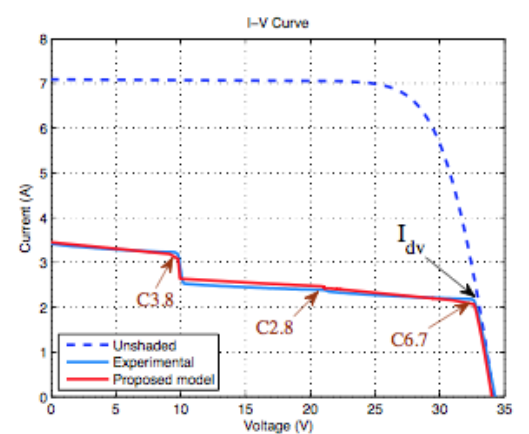

(a) Case 1, monocrystalline

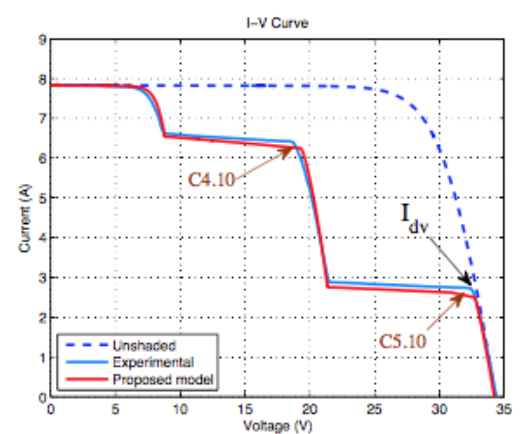

(b) Case 2, monocrystalline

Fig. 5 : I-V curves for two cases tests

Table 3: Shaded area and shadow coefficient for monocrystalline PV module TE2200

\begin{tabular}{ccccccc}
\hline & \multicolumn{3}{c}{ Case 1 } & \multicolumn{3}{c}{ Case 2 } \\
\hline Group & Cell & $a_{s}$ & $\delta_{n}$ & Cell & $a_{s}$ & $\delta_{n}$ \\
1 & $\mathbf{C 2 . 8}$ & 0.96 & 0.33 & & & \\
2 & $\mathbf{C 3 . 8}$ & 0.80 & 0.44 & $\mathbf{C 4 . 1 0}$ & 0.25 & 0.82 \\
3 & $\mathbf{C 6 . 7}$ & 0.98 & 0.31 & $\mathbf{C 5 . 1 0}$ & 0.91 & 0.34
\end{tabular}

The mean square error (MSE) is used to validate the proposed model with the experiment test. The MSE (Equation (14)) values in Table 4 illustrate the model accuracy. Therefore, the proposed model is suitable for describing the current-voltage behavior of partially shaded PV modules.

$$
M S E=\frac{1}{n} \sum_{i=1}^{n}\left(e_{i}\right)^{2}
$$

The results of the experiments show that the shadow coefficient $\delta$ is directly affected by changes in the I-V curve. The PV cell with the lowest value of $\delta$ in the PV module causes the lowest divergence-current point in the I-V curve. For instance, the first divergence point in the $\mathrm{I}-\mathrm{V}$ curve is caused by cell 6.7 of group 3 for Case 1 of the monocrystalline PV module TE2200. In Case 2, the lowest point in the I-V curve is caused by cell C5.10.

Table 4: Model accuracy of the proposed PV model

\begin{tabular}{lll} 
& Case 1 & Case 2 \\
\hline MSE & $0.92 \%$ & $1,07 \%$ \\
\hline
\end{tabular}

The proposed partially model shows the importancy to develop a hot-spot prevention in order to avoid all temperature increase. The next section presents the two cases of studies with the I-V curves in complex shading conditions. For each case, the evolution of the standard error will be analyzed to extract a general set of interpretation rules which will permit to identify problems of hot-spot. This method shows the area of fault detection that characterizes the presence of a non-uniform shadow on PV array, affecting drastically the PV 
performance. The method and the implementation process of the proposed model will be explained to show the importancy to have a faster hot-spot prevention.

\section{Hot-spot prevention and shaded PV systems emulator}

\subsection{Hot-spot prevention method}

The developed PV emulators should be able to emulate more complicated test cases with appropriate transient responses as shown above with the both cases. The development of partial shading PV emulators with a fault detection is proposed regarding power electronic converters for decentralized PV systems and the apparition of higher switching frequency of transistors. The real-time emulation of complex shaded PV models with fault detection application can achieve the performance and accuracy requirements. Bypass diodes are used to mitigate the presence of hot-spot, but it does not prevent hot spotting or the damage it causes. The study of Kim proposed a string-level hot-spot detection concept that measures changes in the string's small-signal impedance to identify hot spotting [30]. The Itako's paper [31] presents a development of real time hotspot detection system using scanmethod about the PV solar panel I-V characteristic to distinguish between normal cells and hot-spot cells depending on the changes of the panel output current in real time. There is a vast collection of hot-spot detection focused on MPPT applications.

The proposed method revisits the idea of using a first derivative calculation to prevent the presence of Hot-spot validated firstly in simulation [12]. The complete process of implementation is performed in FPGA decreasing the computation time and responding of the complexity of shaded PV models and its application of hot-spot prevention. The study of transients and fast response is essentially used with data mining techniques to compare real-time measurement [7]. The I-V curve acquired during shading conditions is compared to a reference I-V curve issue to a validated solar model. Their comparison is made through the estimation of the standard error using the current from the shaded and reference I-V curves, as defined in Equation (15).

$$
E(i)_{s \tan \text { dard }}=\frac{I(i)_{\text {reference }}-I(i)_{\text {shaded }}}{\max \left(I(i)_{\text {reference }}-I(i)_{\text {shaded }}\right)}
$$

Where $E(i)_{\text {standard }}$ is the standard error of the ith I-V curve point, $I(i)_{\text {reference }}$ is the current of I-V curve under reference conditions and $I(i)_{\text {shaded }}$ is the current of the I-V curve acquired under shaded conditions. The standard error is calculated for all of the points composing the I-V curve and its variation in relation to the PV voltage is used to monitor any changes in the shaded I-V curve as a whole. This derivative is calculated through the Equation (16).

$$
\frac{d E(i)_{s \tan d a r d}}{d V_{\bmod u l e}}=\frac{E(i+1)_{s \tan \text { dard }}-E(i)_{s \tan \text { dard }}}{V(i+1)_{\bmod \text { ule }}-V(i)_{\bmod \text { ule }}}
$$

Where $V(i)_{\text {module }}$ is the voltage of the ith I-V curve point.

The results of the proposed model has been validated with the apparition of positive and negatives peaks which correspond respectively at the presence of uniform shadow and non-uniform shadow. The positive peak shifts to lower voltage values as the shadow area becomes wider. The negative peak shifts to voltage values close to the 
open-circuit voltage for severe cases of non-uniform shading. The case where the positive peak is closed to the short-circuit current proved a failure of the bypass diode.

\subsection{Implementation and results}

Emulation of shaded PV systems and hot-prevention requires powerful processing devices such as FPGAs. The proposed model and the hot-spot algorithm has been designed using the very high-speed description language (VHDL) and implemented on Xilinx ZedBoard. Using different parts of the FPGA structure, the functional blocks of FPGA such as memory and logic resources work in parallel with very high frequency offering high execution speed. On the first hand, it is necessary to reduce the execution speed consuming less FPGA hardware resources. On the second hand, insufficient number of bits uses can affect the whole system in precision reduction and calculation errors.

Fig. 6 shows the real-time FPGA-based platform for emulation of complex shaded PV systems. The processing time to evaluate a point in the I-V curve is $10.5 \mu$ s and approximately $4 \mathrm{~ms}$ to generate an I-V curve suitable to realtime applications according to fast computing methods reported in literature. Related works of fast computing methods for PV modeling such as [32] present a response time of $23 \mathrm{mS}$ to compute an unshaded I-V curve or authors in [33] argue a computing time around $10 \mu \mathrm{S}$ to evaluate a complex thermal and electrical PV model.

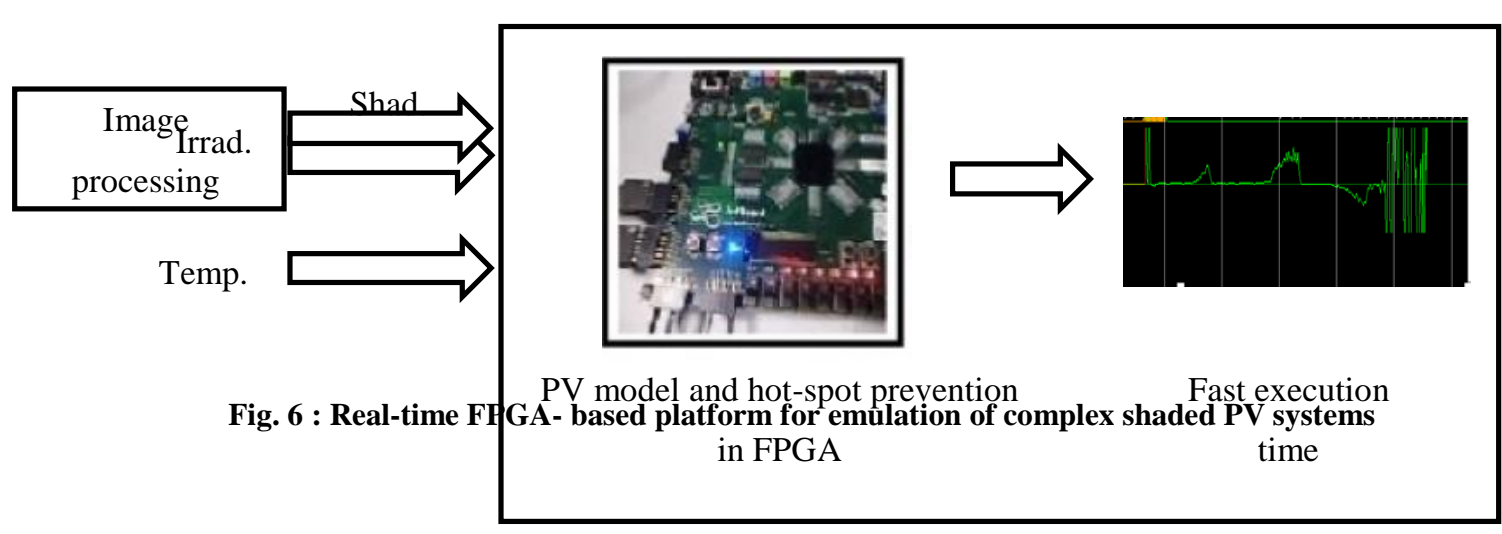

The next step of the work is to implement the hot-spot prevention method in the zedboard. Fig. 7 shows the VHDL flowchart of the presented method of hot-spot prevention. Step 1 consists to calculate the maximum value of the difference between the reference current and the shaded current. The emulator gives 256 points of I-V curves measurements as the I-V tracer Mp-160. The execution time of this step is $2.77 \mu$ s which depends on the execution time of the used FPGA board, in this case 10ns. Step 2 uses the Equation (15) in order to know the normalize error of the both current. The execution time of this part is $2.53 \mu$ s. The different value is stored in the ROM memory in order to perform the Equation (16) calculation. Step 3 allows to start the hot-spot prevention calculating. The

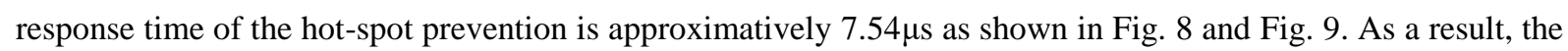
total response time to obtain the I-V curves and to perform the hot-spot prevention is $18 \mu \mathrm{s}$. 


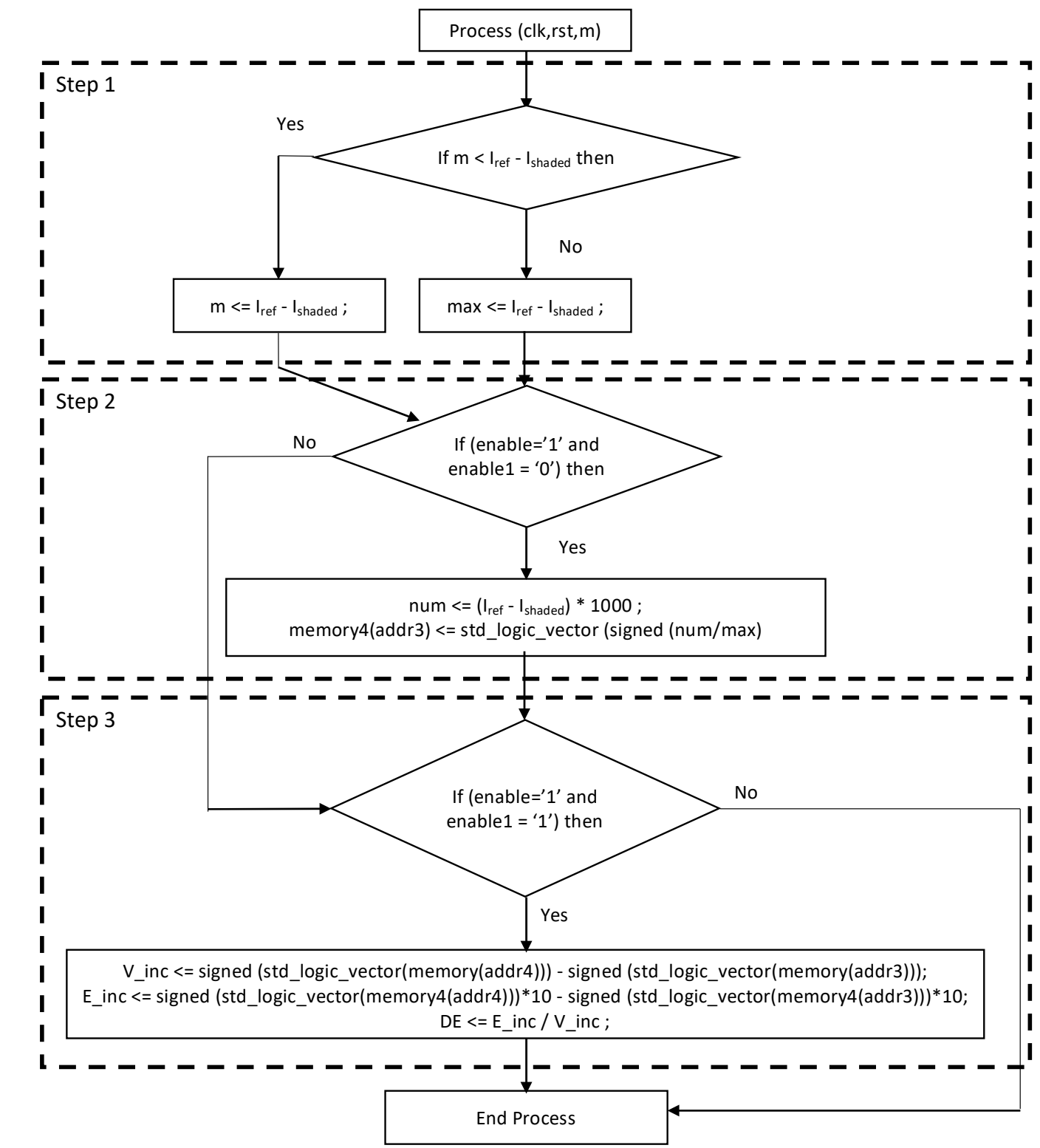

Fig. 7 : VHDL flowchat of the Hot-spot prevention

Fig. 8

and Fig. 9 show the process simulation In VHDL of the hot-spot prevention with the response time for both cases of the study presented in part 2. For Case1, the positive peak can be seen which caracterizes the activation of only bypass diode. The negative peak shifts to voltage values close to the open-circuit voltage for severe cases of nonuniform shading. For Case 2, two postive peaks characterize the presence of the activation of two bypass diodes. The amplitud of the positive peak depends on the area of the shadow which can be more important and can accelerate the hot-spot apparition in non-uniform shading cases. 


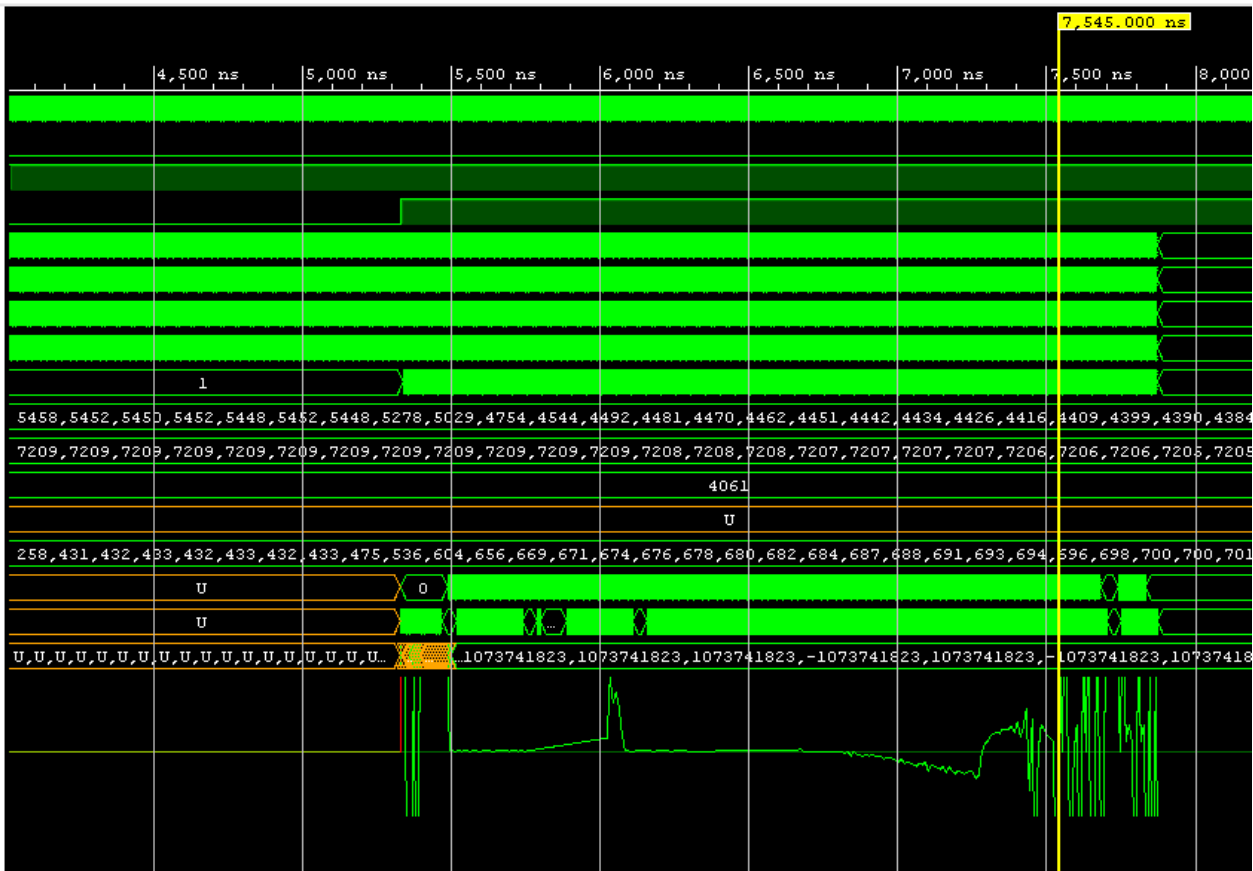

Fig. 8 : Hot-spot prevention results and response time for Case 1

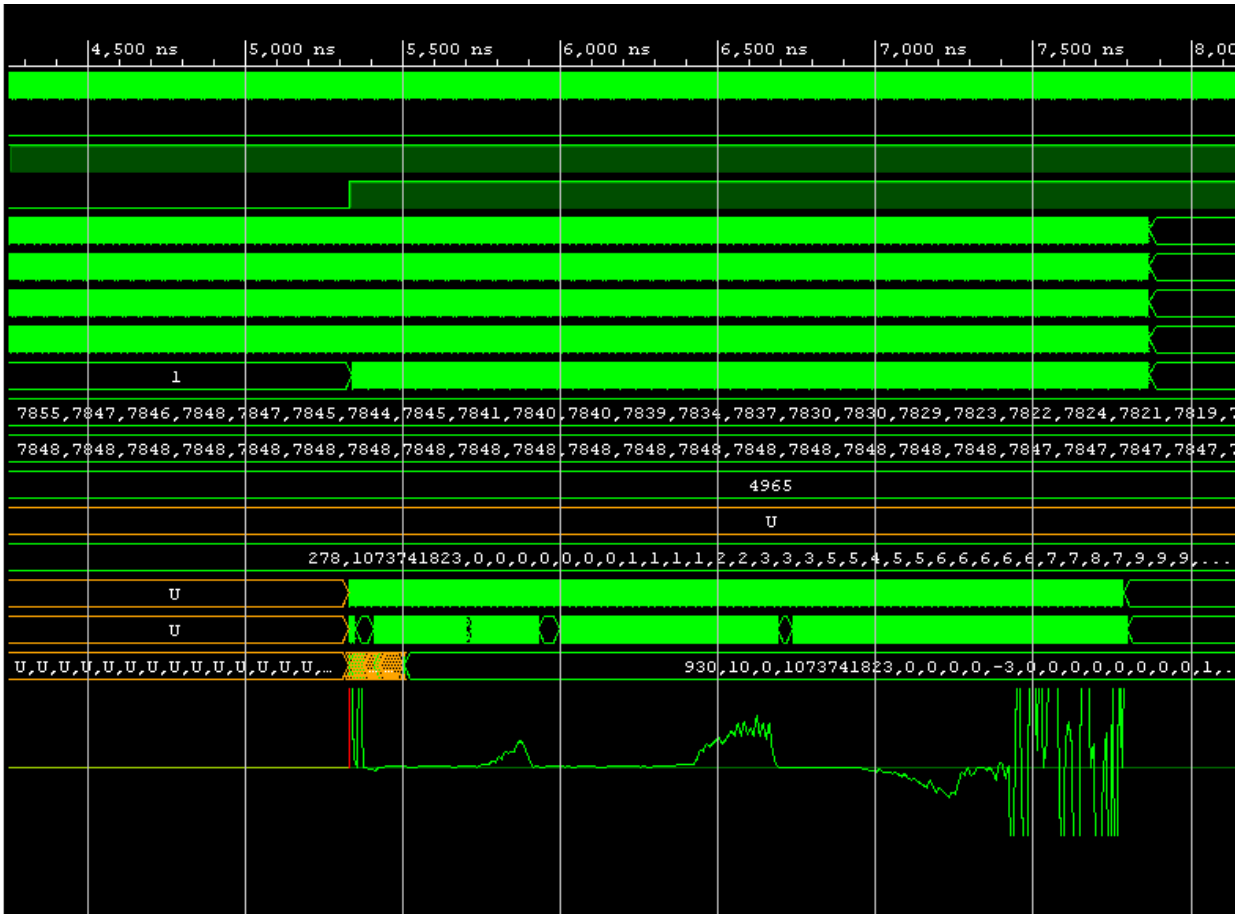

Fig. 9 : Hot-spot prevention results and response time for Case 2

4. Conclusions

337 The shading effect on PV module is one of the main causes of inefficiency and degradation of PV modules losses. A partially shaded PV cell enters the hotspot condition faster than a fully shaded PV cell. It is important to develop accurate and faster tools as an emulator to avoid all form of hot-spot appartition. This paper presents a methodology

340 for modeling complex partially shaded PV modules and a hot-spot prevention method. The proposed approach

341 defined a simplified relation using a shadow coefficient $\delta$ that is suitable for describing the relation between the 
shaded area and shading factor with the partial shading behavior. The proposed emulator allows to study the high non-linearity and the complexity of PV systems in partial shading with a hot-spot prevention. The faster total time response of the emulator responds to the demand and to the optimization of power transistors which permit to get greater-high efficiency, high power density and to achieve higher switching frequency. The first perspective work is to investigate the development of a real-time monitoring system able to obtain I-V curves without perturbing PV production in order to connect the FPGA emulator. The second step is to develop the fault detection to avoid the apparitions of hot spot. An active fault tolerant control is one of the fault detection method allowing to detect the positive peak, the area of detection and the part of the non-uniform shadow characterizing the appartition of a hot-spot.

\section{References}

[1] M.C Alonso-Garcia, J.M Ruiz, F. Chen lo, "Experimental study of mismatch and shading effects in the I-V characteristic of a photovoltaic module”, Solar Energy Materials \& Solar Cells 90, 2006, 329-340.

[2] A. Woyte, J. Nijs, R. Belmans, "Partial shadowing of photovoltaic arrays with different system configurations: literature review and field test results”, Solar Energy, Volume 74, Issue 3, March 2003, Pages 217-233.

[3] Suk Whan Ko, Young Chul Ju, Hye Mi Hwang, Jung Hun So, Young-Seok Jung, Hyung-Jun Song, Hee-eun Song, Soo-Hyun Kim, Gi Hwan Kang, "Electric and thermal characteristics of photovoltaic modules under partial shading and with a damaged bypass diode”, In Energy, Volume 128, 2017, Pages 232-243.

[4] P. Guerriero, V. d'Alessandro, L. Petrazzuoli, G. Vallone and S. Daliento, "Effective real-time performance monitoring and diagnostics of individual panels in PV plants," 2013 International Conference on Clean Electrical Power (ICCEP), Alghero, 2013, pp. 14-19.

[5] R. Platon, J. Martel, N. Woodruff and T. Y. Chau, "Online Fault Detection in PV Systems," in IEEE Transactions on Sustainable Energy, vol. 6, no. 4, pp. 1200-1207, Oct. 2015.

[6] W. Chine, A. Mellit, A. Massi Pavan, S.A. Kalogirou, "Fault detection method for grid-connected photovoltaic plants", Renewable Energy, Volume 66, 2014, Pages 99-110.

[7] L. Serrano-Luján, J. M. Cadenas, J. Faxas-Guzmán, A. Urbina, “Case of study: Photovoltaic faults recognition method based on data mining techniques", Journal of Renewable and Sustainable Energy, Volume 8, Issue 4, Pages 043506, 2016.

[8] Santiago Silvestre, Aissa Chouder, Engin Karatepe, “Automatic fault detection in grid connected PV systems”, Solar Energy, Volume 94, 2013, Pages 119-127.

[9] J. Solórzano, M.A. Egido, “Automatic fault diagnosis in PV systems with distributed MPPT”, Energy Conversion and Management, Volume 76, 2013, Pages 925-934

[10] Siva Ramakrishna Madeti, S.N. Singh, “Online modular level fault detection algorithm for grid-tied and offgrid PV systems", Solar Energy, Volume 157, 2017, Pages 349-364

[11] K. A. Kim and P. T. Krein, "Reexamination of Photovoltaic Hot Spotting to Show Inadequacy of the Bypass Diode," in IEEE Journal of Photovoltaics, vol. 5, no. 5, pp. 1435-1441, Sept. 2015.

[12] M. Bressan, Y. El Basri, A.G. Galeano, C. Alonso, “A shadow fault detection method based on the standard error analysis of I-V curves”, In Renewable Energy, Volume 99, 2016, Pages 1181-1190.

[13] Yaw-Juen Wang, Po-Chun Hsu, “An investigation on partial shading of PV modules with different connection configurations of PV cells", In Energy, Volume 36, Issue 5, 2011, Pages 3069-3078. 
[14] S. Silvestre, A. Boronat, A. Chouder, "Study of bypass diodes configuration on PV modules", In Applied Energy, Volume 86, Issue 9, 2009, Pages 1632-1640.

[15] S. Daliento, F. Di Napoli, P. Guerriero, V. d'Alessandro, “A modified bypass circuit for improved hot-spot reliability of solar panels subject to partial shading”, In Solar Energy, Volume 134, 2016, Pages 211-218

[16] D. Rossi, M. Omaña, D. Giaffreda and C. Metra, "Modeling and Detection of Hot-spot in Shaded Photovoltaic Cells," in IEEE Transactions on Very Large Scale Integration (VLSI) Systems, vol. 23, no. 6, pp. 1031-1039, June 2015.

[17] Y. Zhao, B. Lehman, R. Ball, J. Mosesian, J. F. de Palma, “Outlier detection rules for fault detection in solar photovoltaic arrays", Applied Power Electronics Conference and Exposition (APEC), 2013 Twenty-Eighth Annual IEEE, 2913 - 2920

[18] T. Takashima, J. Yamaguchi, K. Otani, K. Kato, and M. Ishida, "Experimental studies of failure detection methods in PV module strings", Photovoltaic Energy Conversion, Conference Record of the 2006 IEEE 4th World Conference, Page(s): 2227-2230

[19] Y. Hirata, S. Noro, T. Aoki, and S. Miyazawa, "Diagnosis Photovoltaic Failure by Simple Function Method to Acquire I-V Curve of Photovoltaic Modules String", Photovoltaic Specialists Conference (PVSC), 2012 38th IEEE, Page(s): 1340-1343

[20] V. d'Alessandro, F. Di Napoli, P. Guerriero, S. Daliento, “An automated high-granularity tool for a fast evaluation of the yield of PV plants accounting for shading effects”, In Renewable Energy, Volume 83, 2015, Pages 294-304

[21] Tuan Dat Mai, Sven De Breucker, Kris Baert, Johan Driesen, "Reconfigurable emulator for photovoltaic modules under static partial shading conditions", In Solar Energy, Volume 141, 2017, Pages 256-265.

[22] Z. Pang, X. Ren, J. Xiang, Q. Chen, X. Ruan and W. Chen, "High-frequency DC-DC converter in electric vehicle based on GaN transistors," 2016 IEEE Energy Conversion Congress and Exposition (ECCE), Milwaukee, WI, 2016, pp. 1-7.

[23] J. W. Bishop, "Microplasma breakdown and hot-spots in silicon solar cells,” Solar Cells, vol. 26, no. 4, pp. 335-349, 1989.

[24] K. A. Kim, P.T. Krein, "Photovoltaic hot-spot analysis for cells with various reverse-bias characteristics through electrical and thermal simulation" in Proc. IEEE Workshop Control Modeling Power Electron., Jun. 2013, pp 1-8.

[25] F. E. Lahouar, M. Hamouda and J. Ben Hadj Slama, "Design and control of a grid-tied three-phase three-level diode clamped single-stage photovoltaic converter," 2015 Tenth International Conference on Ecological Vehicles and Renewable Energies (EVER), Monte Carlo, 2015, pp. 1-7.

[26] J.W Bishop, "Computer Simulation of the effects of electrical mismatches in photovoltaic cell interconnection circuit”, ESTI Project, Commission of the European Communities Joint Research Centre, 1988.

[27] W. Hermann, W. Wiesner, W. Vaaben, "Hot spot investigations on PV modules-new concepts for a test standard and consequences for module design with respect to bypass diodes", Photovoltaic Specialists Conference, 1997., Conference Record of the Twenty-Sixth IEEE, Page(s): 1129-1132.

[28] S. Guo, T. M. Walsh, A. G. Aberle, and M. Peters, “Analysing par- tial shading of pv modules by circuit modelling," in 2012 38th IEEE Photovoltaic Specialists Conference, pp. 002957-002960, June 2012. 

Emulation of its Components Using HiLeS". Micro and nanotechnologies/Microelectronics. Université de Toulouse 3 Paul Sabatier, 2017.

[30] K. A. Kim, G. S. Seo, B. H. Cho and P. T. Krein, "Photovoltaic Hot-Spot Detection for Solar Panel Substrings Using AC Parameter Characterization," in IEEE Transactions on Power Electronics, vol. 31, no. 2, pp. 1121-1130, Feb. 2016. [31] K. Itako, B. Hossam, T. Kudoh and Q. Huang, "Development of real time hotspot detection system using scan-method for PV generation system," IECON 2015 - 41st Annual Conference of the IEEE Industrial Electronics Society, Yokohama, 2015, pp. 001032-001036. high-accuracy photovoltaic emulator system using $\{$ ARM $\}$ processors," Solar Energy, vol. 120, pp. $389-398$, 2015. [33] J.-H. Jung and S. Ahmed, "Real-time simulation model development of single crystalline photovoltaic panels using fast computation methods," Solar Energy, vol. 86, no. 6, pp. 1826 - 1837, 2012.

434 